\title{
Buffer's ionic strength on the chaperone-like activity (CLA) of silkworm small heat shock protein: sHSP19.9 and sHSP20.8
}

\author{
M. Tofazzal Hossain ${ }^{1^{*}}$ and Yoichi Aso ${ }^{2}$ \\ ${ }^{1}$ Department of Biochemistry and Molecular Biology, Faculty of Agriculture, Bangladesh Agricultural University, \\ Mymensingh-2202, Bangladesh, ${ }^{2}$ Institute of Genetic Resources, Faculty of Agriculture, Kyushu University, Fukuoka \\ 812-8581, Japan, E-mail: mthossain@bau.edu.bd
}

\begin{abstract}
Small heat-shock proteins (sHSPs), an abundant and ubiquitous family of molecular chaperones, can effectively prevent irreversible aggregation of non-native proteins by forming soluble complex. The CLA of sHSPs is usually determined by the capacity to suppress thermally or chemically induced protein aggregation. Various factors can effectively influence the CLA, and among them the ionic strength of the preparation and working buffer is an important factor. The study deals with the effect of ionic strength of buffer on the CLA of two silkworm sHSPs: namely sHSP19.9 and SHSP20.8 against the thermally-induced aggregation of BLC, a non-native protein. The study clearly revealed that SHSP19.9 required high ionic strength (more $\mathrm{NaCl}$ concentration) in reaction buffer to prevent irreversible aggregation of BLC. On the other hand, such high ionic strength condition is not necessary for sHSP20.8 but it influences the activity in some context.
\end{abstract}

Keywords: lonic strength of buffer, CLA, silkworm, sHSP19.9, sHSP20.8

\section{Introduction}

Accumulation of the aggregated proteins, in response to different environmental stresses, possess a serious threat to cellular viability as aggregated proteins are toxic to the cells and they impair the normal cellular functions (Horwich, 2002). In this situation cell increases the application of different defense mechanisms including the expression of several classes of proteins usually called heat shock proteins (HSPs) (Lindquist and Craig, 1988). The major conserved families of these HSPs have been shown to be involved as molecular chaperones in protein folding to assisting other cellular proteins to be remained in native state (Beissinger and Bucher, 1998; Jiao et al., 2005). The most divergent of these chaperones classes is small heat shock proteins (sHSPs), which contained conserved amino acid sequences so called $\alpha$-crystalline domain. This domain can effectively and strongly bind to the aggregation-prone nonnative proteins. Such interaction prevents the accumulation of heat denatured protein aggregates and suppresses their aggregation (Jakob et al.; 1993, Haslbeck and Bucher, 2002; Parsell et al.; 1994, Stromer et al., 2003).

BLC is a ubiquitous enzyme present in aerobic organisms, which is readily aggregated and inactivated at $60^{\circ} \mathrm{C}$. It catalyzes the disproportionation of $\mathrm{H}_{2} \mathrm{O}_{2}$ to molecular oxygen and waters (Hook and Harding, 1997). So it was used as a target protein to observe the CLA of sHSP20.8 and sHSP 19.9 at $60^{\circ} \mathrm{C}$. In the presence of low ionic strength buffer, sHSP19.9 was aggregated, which is an abnormal property of sHSPs. Whereas SHSP20.8 was stable and can show its CLA. But SHSPs should suppress the nonnative protein aggregation at any stress condition. When it was seemed to be failed to make it stable at heat stress condition, then we thought to change the buffer ionic strength from low to high ionic strength. sHSP20.8 was used as standard to observe and compare the activity of sHSP19.9 against the heat-induced aggregation of BLC.

\section{Materials and Methods}

\section{Chemicals used}

Preparation and purification of different chemicals used are as follows and all other reagents used were of analytical grade without further purification. 


\section{Purification of sHSPs}

Overproduction of sHSPs by $E$. Coli cells and purification of the overproduced sHSPs were done as described by Hossain and Aso (2010). Thus N-terminal His-tagged recombinant sHSPs were prepared. Protein amounts for sHSP19.9 and sHSP20.8 were calculated using molar extinction coefficients $\left(\varepsilon_{280}\right)$; $19940 \mathrm{~cm}^{-1} \mathrm{M}^{-1}$ and $22585 \mathrm{~cm}^{-1} \mathrm{M}^{-1}$, respectively (Pace et al., 1995).

\section{Buffer used}

Unless otherwise noted, the used buffers were $50 \mathrm{mM}$ sodium phosphate $(\mathrm{pH} 8.0)$ containing $0.1 \mathrm{M} \mathrm{NaCl}$ (buffer A), containing $0.3 \mathrm{M} \mathrm{NaCl}$ (buffer B), and 20 mM HEPES (pH 7.7) containing $10 \mathrm{mM} \mathrm{NaCl}$ (buffer $\mathrm{C}$; low ionic strength buffer).

\section{Preparation of BLC solution and assay of BLC activity}

BLC was purchased from Sigma (Tokyo, Japan). BLC solution was freshly prepared with the above mentioned buffers where necessary and used without further purification. Concentration of the BLC was determined by spectrophotometry, using $\varepsilon_{280}=93.706 \mathrm{mM}^{-1} \mathrm{~cm}^{-1}$ (Decker, 1977).

\section{Thermal aggregation assay of BLC}

Concentration-, time- and ionic strength- dependent thermal aggregation of BLC was monitored at $60^{\circ} \mathrm{C}$ by spectrophotometer (Shimadzu UV-2400) in the presence of buffer C. For the first one, different concentration of BLC ranged from 5.20 to $13.0 \mu \mathrm{M}$ was used, for the second one, $5.0 \mu \mathrm{M}$ BLC was used to monitor the aggregation up to $30 \mathrm{~min}$ with $5 \mathrm{~min}$ intervals and for the last one, $5.0 \mu \mathrm{M}$ BLC with different $\mathrm{NaCl}$ concentration (ionic strength); $0.01 \mathrm{M}, 0.1 \mathrm{M}$ and $0.3 \mathrm{M}$ containing $20 \mathrm{mM}$ HEPES was used and the mode of aggregation was studied at $360 \mathrm{~nm}$.

\section{CLA of SHSP19.9 and SHSP20.8 in the presence of high ionic strength buffers:}

sHSP19.9 was thermally aggregated at $60^{\circ} \mathrm{C}$ in the presence of buffer $\mathrm{C}$, which was suppressed in the presence of high ionic strength buffers, its self aggregation was suppressed (Hossain et al., 2010). So, high $\mathrm{NaCl}$ concentration in the buffer, the CLA of sHSP19.9 against BLC aggregation was monitored. Two different methods; 96-wells plate (Bio-Rad) and spectrophotometer were used to observe the CLA of sHSP19.9 in the presence of buffer A. For 96-well plate method, the activity was observed with different concentration of sHSP19.9 such as 0 (control), 0.025, 0.05, 0.075, 0.10, 0.125, 0.150, 0.175 and 0.20 $\mathrm{mg} / \mathrm{ml}$ against fixed concentration $(5.0 \mathrm{mg} / \mathrm{ml})$ of BLC. Absorbance was monitored by microplate reader (Bio-Rad) at $595 \mathrm{~nm}$. For spectrophotometer, the activity was observed at $415 \mathrm{~nm}$ for 20 min with a series of molar concentration ratio such as 1:0 (control; BLC 5.0 $\mu \mathrm{M}$ only), 1:0.1, 1:0.2, 1:0.5, 1:1 and 1:2. Molar concentration ratio-dependent CLA of SHSP19.9 against BLC aggregation in the presence of same buffer was also monitored at $415 \mathrm{~nm}$. The used molar concentration ratio was kept at 1:1 (fixed) but their concentration was different such as 5.0, 7.5 and $30.0 \mu \mathrm{M}$ for each.

Beside buffer $A$, other high ionic strength buffers such as $0.1 \mathrm{M}$ and $0.3 \mathrm{M} \mathrm{NaCl}$ concentrations containing $20 \mathrm{mM}$ HEPES buffer were also used. For $0.1 \mathrm{M} \mathrm{NaCl}$ containing $20 \mathrm{mM}$ HEPES buffer $(\mathrm{pH}$ 7.7), 1:0 (control; BLC $5.0 \mu \mathrm{M}$ only), 1:0.1, 1:0.2, 1:0.5, 1:1 and 1:2 molar concentration ratio was used. The molar concentration was 1:0 (control; BLC $2.5 \mu \mathrm{M}$ only), 1:1, 1:2, 1:3, 1:4 and 1:8 for $0.3 \mathrm{M} \mathrm{NaCl}$ containing 20 mM HEPES buffer ( $\mathrm{pH} 7.7)$.

On the other hand, various molar concentrations ratio such as 1:0 (control; $5.0 \mu \mathrm{M} \mathrm{BLC}$ only), 1:0.1, 1:0.2, 1:0.5, $1: 1$ and 1:2 for $20 \mathrm{mM}$ HEPES buffer $(\mathrm{pH} 7.7$ ) containing $0.1 \mathrm{M} \mathrm{NaCl}, 1: 0$ (control; $2.5 \mu \mathrm{M} \mathrm{BLC}$ only), 1:0.1, 1:0.2, 1:0.3, 1:0.4, 1:0.5, 1:1 and 1:2 for $20 \mathrm{mM}$ HEPES buffer (pH 7.7) containing $0.3 \mathrm{M}$ $\mathrm{NaCl}$ and 1:0 (control; 5.0 $\mu \mathrm{M} \mathrm{BLC}$ only), 1:0.05, 1:0.1, 1:0.2 and 1:1 for buffer A were used for sHSP20.8. The same molar concentration and the same procedure used for SHSP19.9 were followed for sHSP20.8. 


\section{Complex formation among sHSPs and BLC}

Both sHSPs separately with BLC at $1: 1$ molar concentration ratio was incubated at $60^{\circ} \mathrm{C}$ for 1 hour to observe the probable complex formed among them with high ionic strength $20 \mathrm{mM}$ HEPES buffer $(\mathrm{pH}$ 7.7) containing $0.3 \mathrm{M} \mathrm{NaCl}$. The incubated sample was cooled at room temperature for 1 hour and centrifuged at $14,000 \mathrm{rpm}$ for 20 minutes, and the supernatant was used to observe the existence of protein by spectrum before application to gel filtration column.

\section{Results}

\section{Thermal-induced aggregation of BLC}

BLC is a well-studied enzyme produced by a wide spectrum of eukaryotic and prokaryotic organisms (Switala and Loewen, 2002). BLC was vulnerable to temperature stress and observed to be aggregated at $60^{\circ} \mathrm{C}$. It was evident that the accelerated aggregation was observed with the increased concentration and time of aggregation, which messaged about its concentration- and time- dependent aggregation (Fig. 1). By increasing the ionic strength of the buffers ( $\mathrm{NaCl}$ concentration), BLC showed increased aggregation. BLC shows 4-times more aggregation with 10-times increasing $\mathrm{NaCl}$ concentration (Fig. 2).

\section{CLA of sHSP19.9, in the presence of high ionic strength buffer}

With buffer $\mathrm{A}$ and high $\mathrm{NaCl}$ concentration (0.1 and $0.3 \mathrm{M}$ ) containing $20 \mathrm{mM}$ HEPES buffer (pH 7.7), BLC aggregation was increased but at the same condition, sHSP19.9 showed CLA against the BLC aggregation.

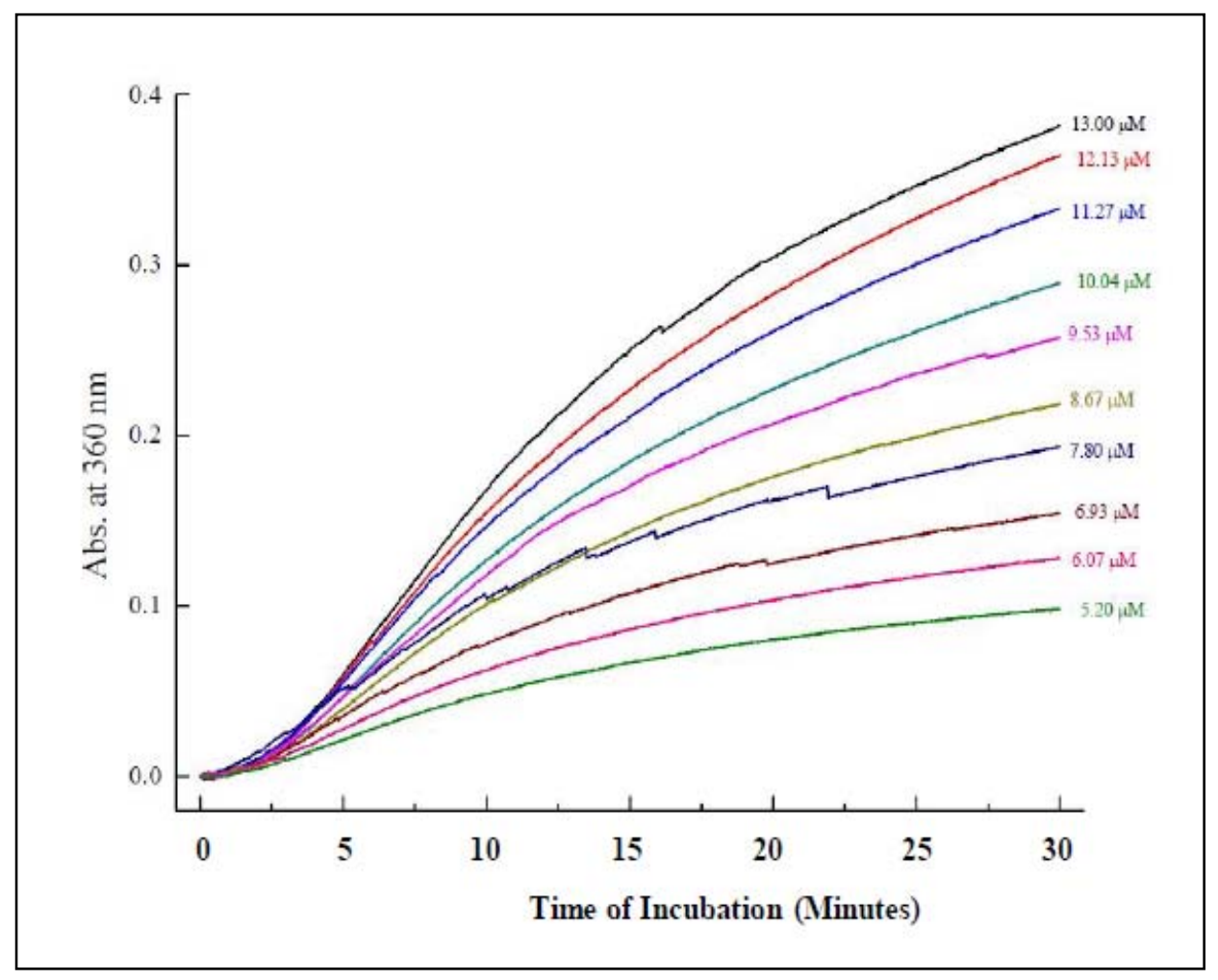

Fig. 1. Time and concentration-dependent thermal aggregation of BLC at $60^{\circ} \mathrm{C}$ in the presence of buffer $\mathrm{C}$ by spectrophotometer method. Various concentration series ranges from 5.20 to $13.0 \mu \mathrm{M}$ and time series from 0 to 30 min were used 


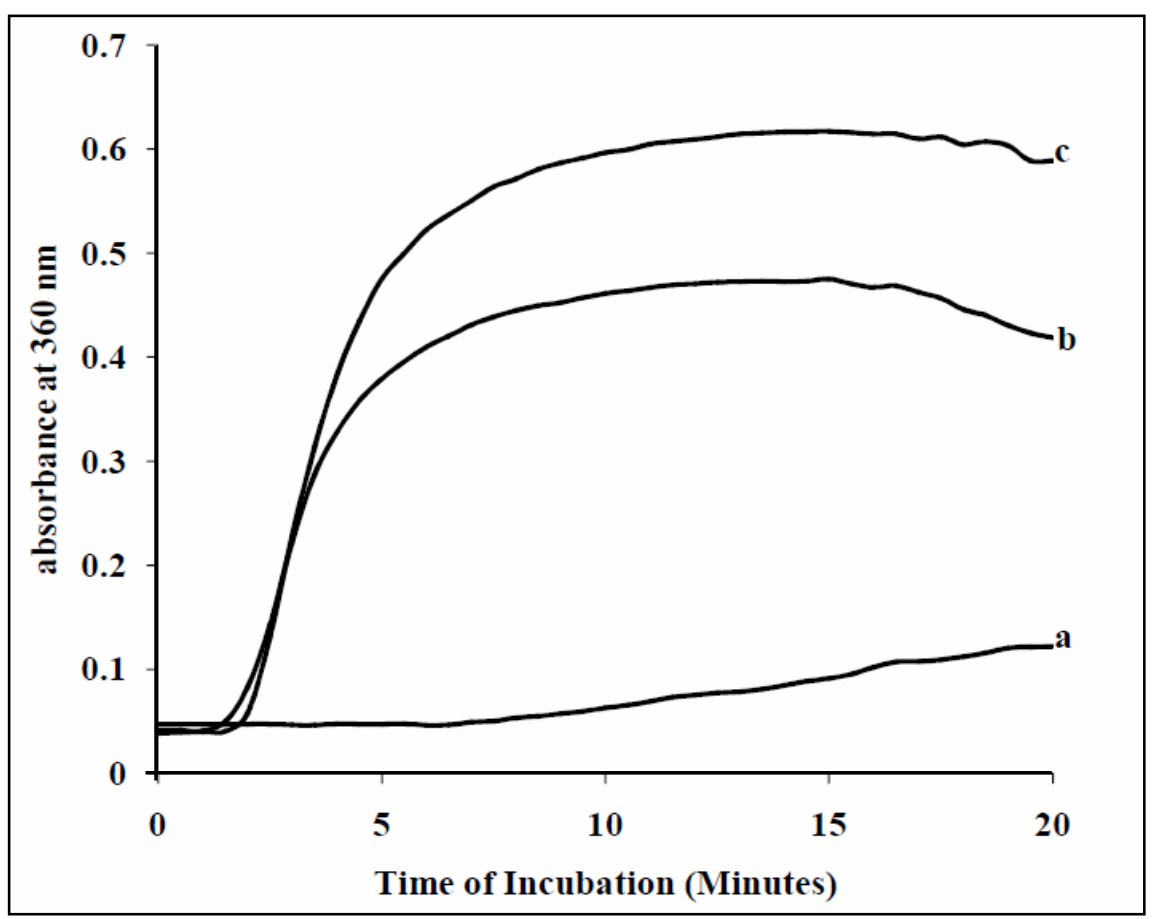

Fig. 2. Thermal-induced aggregation of $\mathrm{BLC}$ at $60^{\circ} \mathrm{C}$ with various ionic strength buffers; $20 \mathrm{mM} \mathrm{HEPES} \mathrm{(pH} \mathrm{7.7)} \mathrm{with}$ various $\mathrm{NaCl}$ concentrations such as a; $0.01 \mathrm{M}$ b; $0.1 \mathrm{M}$ and c; $0.3 \mathrm{M}$

In the presence of buffer A, the effective performance of sHSP19.9 was observed against BLC aggregation (Fig. 3). Maximum aggregation was found for BLC only, where sHSP19.9 was absent. In the presence of sHSP19.9, the aggregation of BLC was decreased and showing the concentration-dependent manner.

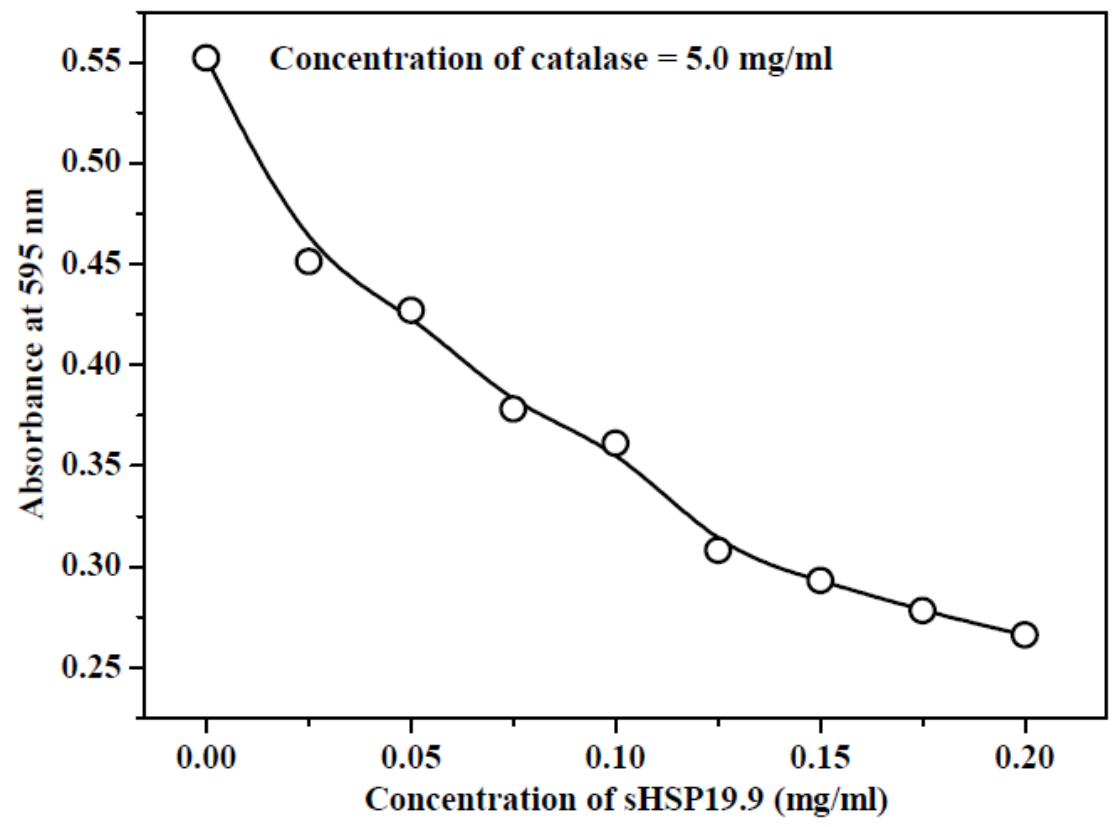

Fig. 3. CLA of sHSP19.9 against BLC aggregation in the presence of buffer A by 96-wells plate (Bio-Rad) method. Various concentrations (ranges from 0 to $2.0 \mathrm{mg} / \mathrm{ml}$ ) of sHSP19.9 were used against fixed $(5.0 \mathrm{mg} / \mathrm{ml})$ concentration of $\mathrm{BLC}$ at $60^{\circ} \mathrm{C}$ 
By using the above mentioned buffer A, the activity of sHSP19.9 was re-examined against BLC aggregation (Fig. 4A). It was also evident that in the presence of buffer A, sHSP19.9 could effectively suppress the heat-induced aggregation of BLC completely at 1:1 concentration ratio.

sHSP19.9 was readily aggregated at $60^{\circ} \mathrm{C}$ in the presence of low ionic strength buffer $\mathrm{C}$ but when the ionic strength of buffer was increased to $0.1 \mathrm{M}$ and more, the aggregation was totally suppressed (Hossain et al., 2010). $20 \mathrm{mM}$ HEPES buffer (pH 7.7) containing $0.1 \mathrm{M}$ (Fig. 4B) and $0.3 \mathrm{M} \mathrm{NaCl}$ (Fig. 5A) were used to observe the CLA of sHSP19.9 against BLC aggregation with various molar concentration ratio. In the presence of former one, sHSP19.9 could never suppress the aggregation of BLC but could enhance the total aggregation slightly at high concentration ratio.

Moreover, in the presence of later one, sHSP19.9 was found to be capable enough to suppress the temperature-induced BLC aggregation at $60^{\circ} \mathrm{C}$. Keeping the same concentration ratio at $1: 1$ but changing the concentration of both BLC and sHSP19.9, the concentration-dependent CLA of sHSP19.9 was examined (Fig. 5B). By increasing the concentration of both proteins above $5.0 \mu \mathrm{M}$, the aggregation was increased, which messaged that above $5.0 \mu \mathrm{M}$, co-precipitation of sHSP19.9 with BLC was happened.

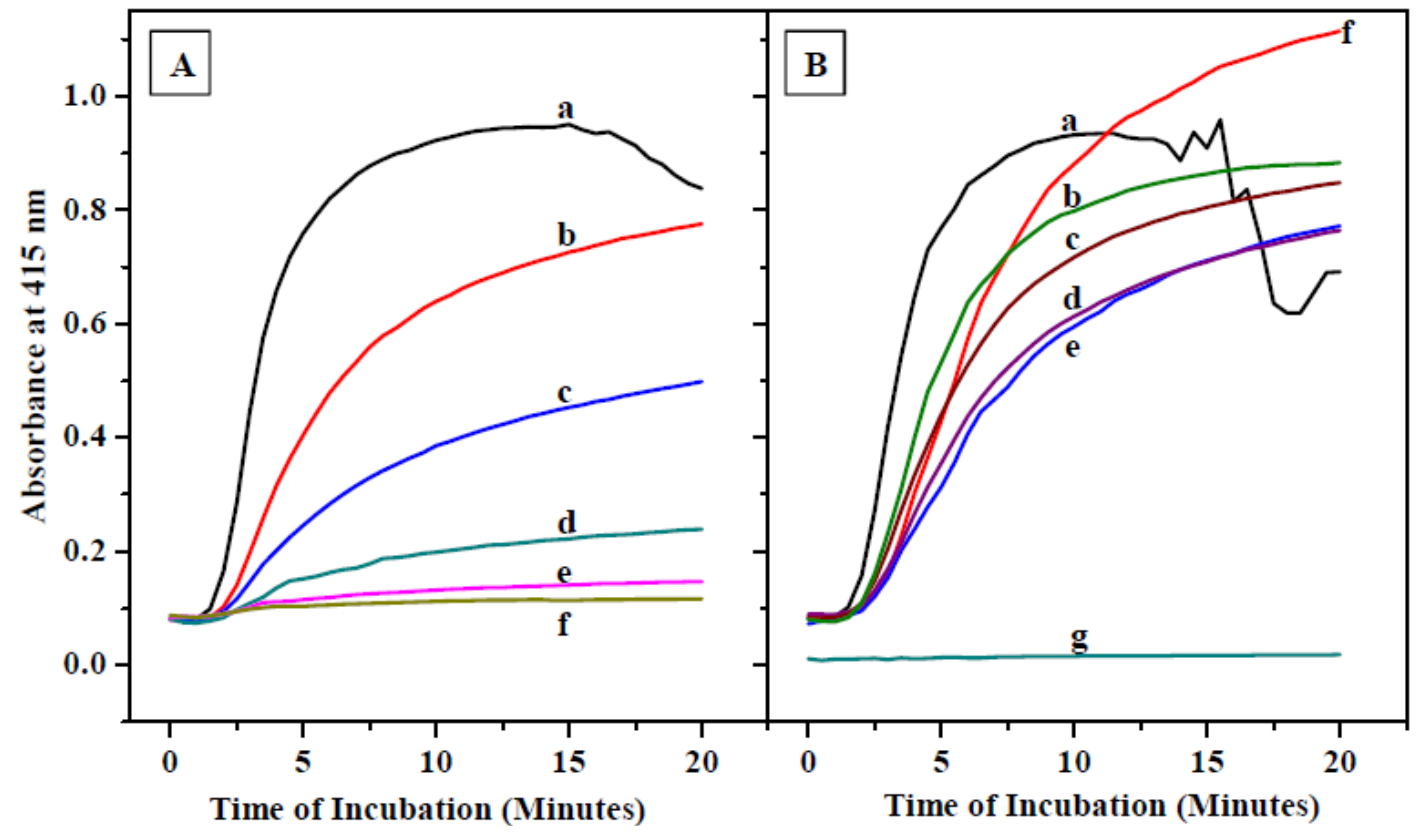

Fig. 4. CLA of SHSP19.9 against BLC aggregation at $60^{\circ} \mathrm{C}$ in the presence of high ionic strength buffers. Panel $A$ shows for buffer $A$ and panel $B$ for $20 \mathrm{mM}$ HEPES buffer $(\mathrm{pH} \mathrm{7.7)}$ containing $0.1 \mathrm{M} \mathrm{NaCl}$ with similar molar ratio for both panels such as 1:0 (a: BLC $5.0 \mu \mathrm{M}), 1: 0.1$ (b), 1:0.2 (c), 1:0.5 (d), 1:1 (e) and 1:2 (f) excepting 0:2 (g: $10.0 \mu \mathrm{M}$ sHSP19.9 only) for panel B

\section{sHSP20.8 against BLC aggregation in the presence of high ionic strength buffer}

CLA of sHSP20.8 against BLC aggregation was also monitored at $60^{\circ} \mathrm{C}$ by spectrophotometer (Shimadzu UV-2400) method at $415 \mathrm{~nm}$ in the presence of high ionic strength buffers such as $20 \mathrm{mM}$ HEPES (pH 7.7) containing $0.1 \mathrm{M} \mathrm{NaCl}$ (Fig. 6A), $20 \mathrm{mM}$ HEPES (pH7.7) containing $0.3 \mathrm{M} \mathrm{NaCl}$ (Fig. 6B) and buffer A (Fig. 7A), respectively. The figures indicated that high ionic strength buffer accelerated the aggregation of BLC. Only after 10 min of incubation, it was precipitated, which was not observed during using of low ionic strength buffer $\mathrm{C}$. sHSP20.8 could suppress the aggregation and precipitation of BLC. The performance was on concentration-dependent and 1:1 molar concentration ratio could suppress the thermal aggregation of BLC completely for all of the mentioned cases.

At the same molar concentration ratio (1:1) but using a range of proteins concentration, the CLA of sHSP20.8 against BLC aggregation was monitored (Fig. 7B). It was observed that 1:1 molar ratio was important not the concentration of proteins. So, the all protein concentrations at 1:1 molar ratio showed the similar activity against BLC aggregation. 


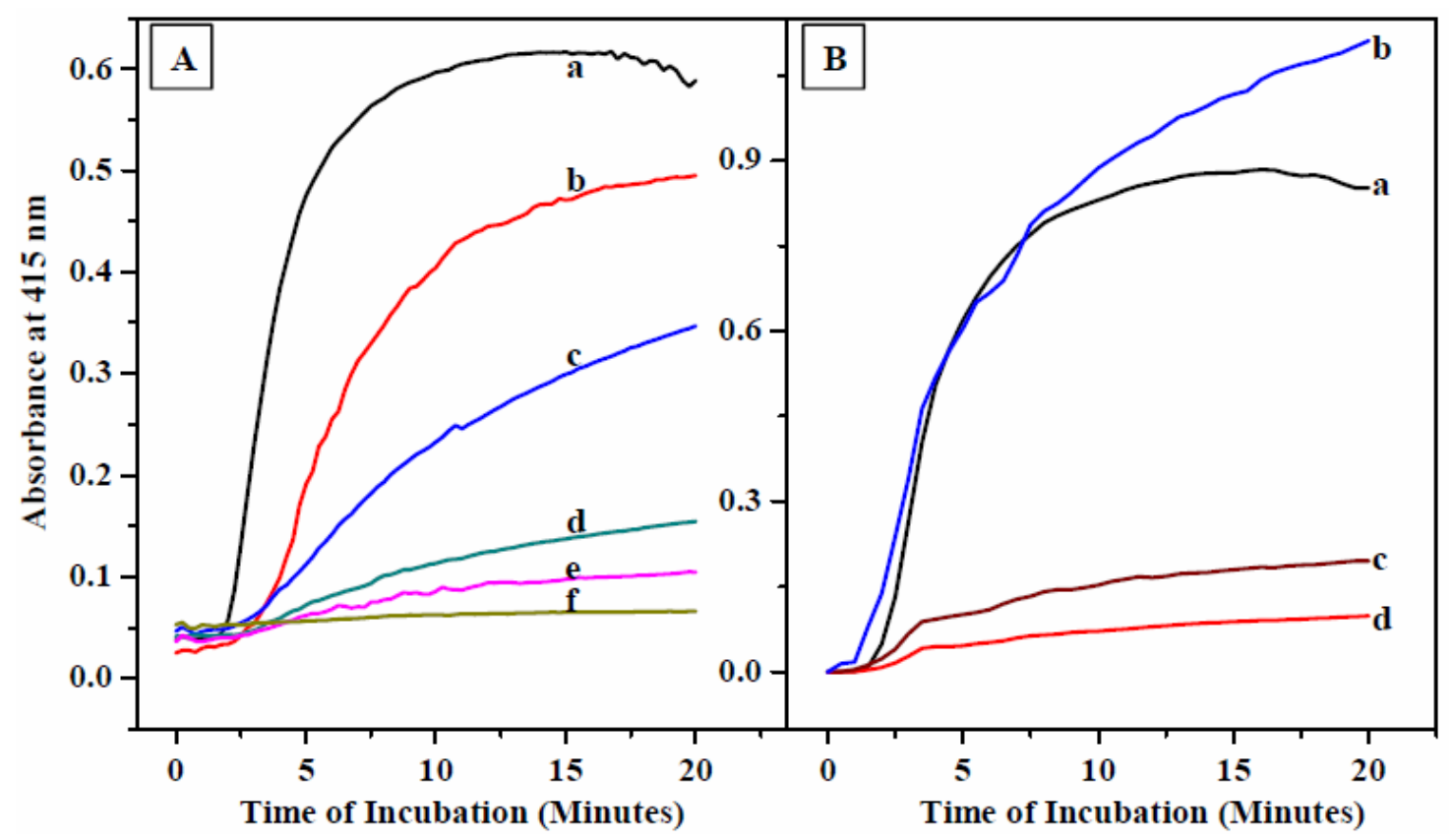

Fig. 5. CLA of sHSP19.9 against BLC aggregation (at $60^{\circ} \mathrm{C}$ ) in the presence of various ionic strength buffers. Panel $A$ shows for $20 \mathrm{mM}$ HEPES buffer $\mathrm{pH} 7.7$ containing $0.3 \mathrm{M} \mathrm{NaCl}$ with various molar ratio such as 1:0 (a: BLC 2.5 $\mu \mathrm{M}$ only), 1:1 (b), 1:2 (c), 1:3 (d), 1:4 (e) and 1:8 (f). Panel B demonstrates fixed 1:1 molar ratio but different concentration such as 5.0 (d), 7.5 (c) and $30.0 \mu \mathrm{M}$ (b) for each of BLC and sHSP19.9 with control (a: BLC 5.0 $\mu \mathrm{M}$ only) in the presence of buffer A.

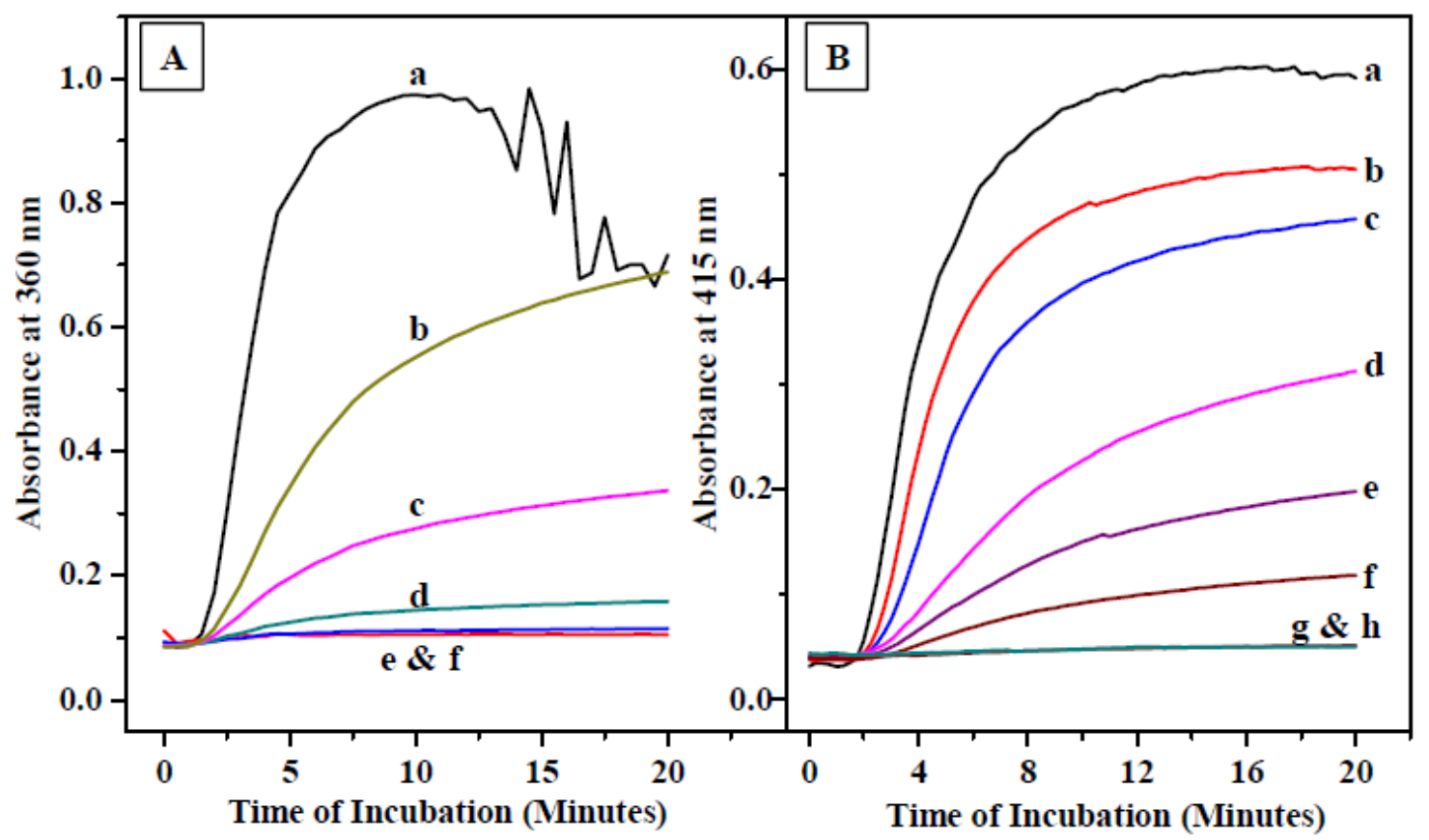

Fig. 6. CLA of sHSP20.8 against BLC aggregation at $60^{\circ} \mathrm{C}$ with high ionic strength buffers by spectrophotometer (Shimadzu UV-2400) method. Panel A represents for $20 \mathrm{mM}$ HEPES buffer ( $\mathrm{pH} 7.7$ ) containing $0.1 \mathrm{M} \mathrm{NaCl}$ with 1:0 (a: BLC $5.0 \mu \mathrm{M}), 1: 0.1$ (b), 1:0.2 (c), 1:0.5 (d), 1:1 (e) and 1:2 (f) molar ratio. Panel B shows for 20 mM HEPES buffer $(\mathrm{pH} 7.7)$ containing $0.3 \mathrm{M} \mathrm{NaCl}$ with 1:0 (a: BLC $2.5 \mu \mathrm{M}), 1: 0.1$ (b), 1:0.2 (c), 1:0.3 (d), 1:0.4 (e), 1:0.5 (f), 1:1 (g) and $1: 2(h)$ molar ratio. 


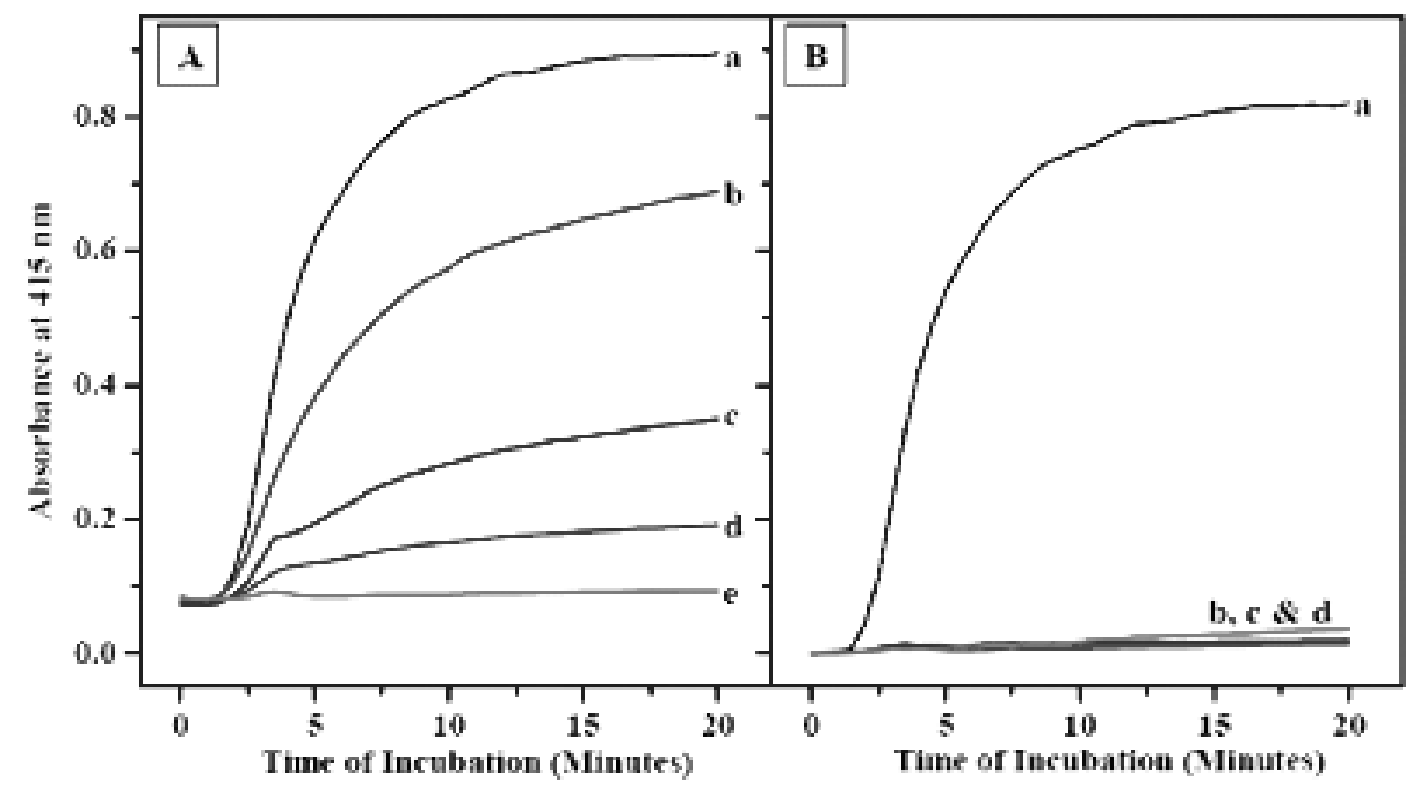

Fig. 7. CLA of sHSP20.8 against BLC aggregation at $60^{\circ} \mathrm{C}$ in the presence of buffer A. Panel A highlights the activity with different molar concentration ratio such as 1:0 (a: BLC 5.0 $\mu \mathrm{M}$ only), 1:0.05 (b), 1:0.1 (c), 1:0.2 (d) and 1:1 (e).In the presence of the same buffer, panel B shows the performance of sHSP20.8 against BLC aggregation with various concentrations but alike molar concentration ratio 1:1 (b: $5.0 \mu \mathrm{M}$ each, c: $7.5 \mu \mathrm{M}$ each and d: $30.0 \mu \mathrm{M}$ each) with control (a: BLC $5.0 \mu \mathrm{M}$ only)

\section{Observation of complex between BLC and sHSPs at high ionic strength}

Although high ionic strength buffer could totally suppress the heat-induced aggregation of sHSP19.9 (Hossain et. al., 2010) and this condition was also favorable to show its CLA against BLA aggregation but probable complex among them was not observed. The spectrums confirmed the existence of both proteins in the supernatant prior to apply to the gel filtration column (Fig. 8). Because the spectrum of the supernatant after incubation and before application to the gel filtration column (Fig. 8b) was seemed to be similar to the spectrum of before incubation (Fig. 8a). But after chromatography no complex forming absorbance was observed (data not shown).

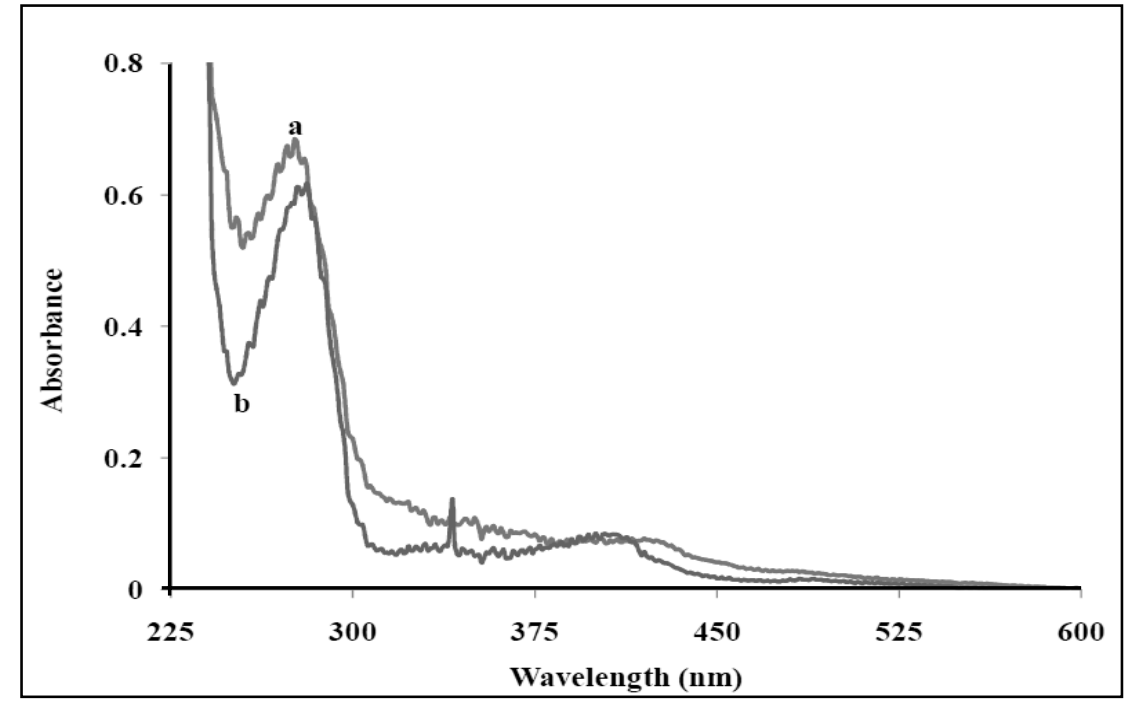

Fig. 8. Spectrum of BLC and sHSP19.9 before incubation (spectrum b) at $60^{\circ} \mathrm{C}$ and after incubation but before application to gel filtration column (spectrum a) 


\section{Discussion}

BLC $\left(\mathrm{H}_{2} \mathrm{O}_{2}: \mathrm{H}_{2} \mathrm{O}_{2}\right.$ oxidoreductase, EC 1.11.1.6) is a tetrameric enzyme with identical subunits each containing a hame prosthetic group (Deissroth and Dounce, 1970; Murthy et al., 1981; Fita and Rossman, 1985). It is known as an antioxidant (Halliwell and Gutteridge, 1990) because of its role in protecting cells from the toxic effects of $\mathrm{H}_{2} \mathrm{O}_{2}$. BLC is rapidly aggregated and inactivated in a progressive manner when it is incubated at $60^{\circ} \mathrm{C}$ losing about $80 \%$ of its original activity within 10 min (Hook and Harding, 1997). Therefore, it was used as substrate protein to observe the CLA of silkworm sHSPs.

sHSP19.9 and SHSP20.8 are two important member of six observed sHSPs in silkworm. sHSP19.9 among them, thermally aggregated at $60^{\circ} \mathrm{C}$ with buffer $\mathrm{C}$ (low ionic strength buffer), whereas sHSP20.8 is remained unchanged. The thermally-induced aggregation of sHSP19.9 is observed to be suppressed in the presence of DTT, high ionic strength buffers and ATP and modification of cys-residues (Hossain et. al., 2010). Among the mentioned factors, only in the presence of high ionic strength buffer sHSP19.9 can suppress the aggregation of BLC completely and in the presence of others, partially but satisfactory (Hossain et. al.,2010, Hossain and Aso, 2013a, Hossain and Aso, 2013b). Like other chaperones, it should have aggregation suppressive activity against aggregation-prone proteins. As high ionic strength buffer can suppress the self aggregation of sHSP19.9 so its activity was monitored against BLC aggregation with its presence. The activities were observed to be concentration-, time- and molar ratiodependent but not as efficient as SHSP20.8. Because SHSP20.8 requires only 1:1 molar concentration ratio to suppress the aggregation of BLC completely whereas, sHSP19.9 needs 8 times more concentration than BLC.

The protein aggregates are toxic to the cells since they impair the normal cellular functions (Horwich, 2002). According to the current model, at environmental stress conditions sHSPs are proposed to prevent the irreversible protein aggregation and insolubilization by binding the non-native proteins to form soluble complex (Haslbeck et al., 1999; Chang et al., 1996; Jackob et al., 1993; Horwich, 1992; Lee and Vierling., 2000). sHSP20.8 can successfully form complex with BLC during incubation (Hossain et al., 2010) but sHSP19.9 is failed. It is evident that SHSP19.9 at high ionic strength condition not only tolerates the heat stress but also interacts with BLC and suppresses its aggregation but sHSP19.9-BLC complex was not revealed (data not shown).

It might be at $60^{\circ} \mathrm{C}$ sHSP19.9 forms a soluble complex with BLC but after cooling and/or centrifugation they are dissociated and resolved in the gel. Because the absorbance curves of sHSP19.9 and BLC mixture before and after incubation are similar to each other. Another phenomenon might also be happened; sHSP19.9 and BLC form soluble aggregate that are not observed by absorbance and after centrifugation is also not precipitated but during Size Exclusion Chromatography, they are resolved by gel and thus the elution fraction occupies no proteins.

\section{Conclusion}

Molecular chaperones such as sHSPs bind partially denatured proteins, thereby preventing irreversible protein aggregation. Silkworm sHSP20.8 and SHSP19.9 were used against the heat-induced aggregation of BLC. High ionic strength not only protects sHSP19.9 from self-aggregation but also makes it effective enough to suppress the aggregation of BLC without forming any complex. This condition is also more favorable for the sHSP20.8 to suppress the BLC aggregation but not a pre-requisite as sHSP19.9.

\section{Acknowledgements}

This work was conducted with the approval of the KEK-PF Proposal Review Committee (Proposal No. 2007G665) and partially sponsored by the Japan Foundation for Applied Enzymology and the National Bio-Resources Project (Silkworm) of the Ministry of Education, Culture, Sports, Science and Technology, Japan. 


\section{References}

Biessinger, M. and Buchner, J. 1998. How chaperones fold proteins. Biol. Chem., 379: 245-259.

Chang, Z., Primm, T.P., Jakana, J., Lee, I.H., Serysheva, I., Chiu, W., Gilbert, H.F., Quiocho, F.A. 1996. Mycobacterium tuberculosis 16-kDa antigen (HSP16.3) functions as an oligomeric structure in vitro to suppress thermal aggregation, J. Biol. Chem. 271: 7218-7223.

Decker, L.A. 1977. Edn. BLC: Worthington Enzyme Manual. Worthington Biochemical Corporation. Freehold, NewJersey, USA, 07728. pp. 63-65.

Deissroth, A., Dounce, A.L. 1970. BLC: Physical and chemical properties, mechanism of catalysis, and physiological role. Physiol. Rev., 50: 319-375.

Fita, I., and Rossmann. M.G. 1985. The active center of BLC. J. Mol. Biol., 1: 21-37.

Halliwell, B. and. Gutteridge, J. M. 1990. Role of free radicals and catalytic metal ions in human disease: an overview. Methods Enzymol., 186:1-85.

Haslbeck, M., Walke, S., Stromer, T., Ehrnsperger, M., White, H.E., Chen, S., Saibil, H.R., Buchner, J. 1999. Hsp26: a temperatureregulated chaperone, EMBO J. 18: 6744-6751.

Haslbeck, M., and Buchner, J. 2002. Chaperone functions in sHSPs: In small stress proteins. Prog. Mol. Subcell. Biol (Ed. A. P. Arrigo and W. E. G. Müller), 28: 37-52.

Hook, D.W.A. and Harding, J.J. 1997. Molecular chaperone protect BLC against thermal stress. Eur. J. Biochem., 247: $380-385$.

Horwich, A.L. 2002. Protein aggregation in disease: a role for folding intermediates forming specific multimeric interactions. J. Clin. Invest., 110: 1221-1232.

Horwitz, J. 1992. Alpha-crystallin can function as a molecular chaperone, Proc. Natl. Acad. Sci. USA 89: 10449-10453.

Hossain, M.T and Aso, Y. 2013a. Chaperone-like activity (CLA) of silkworm sHSP19.9 and sHSP20.8 with dithiothreitol (DTT) against thermal aggregation of bovine liver catalase (BLC). Bangladesh J. Prog. Sci. \& Tech.: 11(1): 049-054.

Hossain, M.T and Aso, Y. 2013b. Silkworm sHSP19.9 and sHSP20.8 with ATP on the thermal induced aggregation of Bovine Liver Catalase (BLC). J. Agrofor. Environ. 7(1): 71-75.

Hossain, M.T. and Aso, Y. 2010. Isolation, purification and thermally-induced property of silkworm small heat shock protein: sHSP19.9 and sHSP20.8. J. Bangladesh Soc. Agril. Sci. Technol., 7(1\&2): 41-46.

Hossain, M.T., Teshiba, S., Shigeoka, Y., Fujisawa, T., Inoko, Y., Sakano, D., Yamamoto, K., Banno, Y. and Aso, Y. 2010. Structural Properties of Silkworm Small Heat Shock Proteins: sHSP19.9 and sHSP20.8. Biosci. Biotechnol. Biochem., 74 (8): $1556-$ 1563.

Jakob, U., Gaestel, M., Engel, K., and Buchner, J. 1993. Small heat shock proteins are molecular chaperones. J. Biol. Chem., 268: $1517-1520$.

Jiao, W., Li, P., Zhang, J., Zhang, H., and Chang, Z. 2005. Small heat-shock proteins function in the insoluble protein complex. Biochem. Biophys. Res. Commun., 335: 227-231.

Lee, G.J., and Vierling, E. 2000. A small heat shock protein cooperates with heat shock protein 70 systems to reactivate a heatdenatured protein. Plant Physiol., 122: 189-198.

Lindquist, S. and Craig, E.A. 1998. The heat shock proteins. Annu. Rev. Genet., 22: 631-667.

Murthy, M.R., Ried, T.J., Sicignano, A., Tanaka, N., Rossmann, M.G. 1981. Structure of beef liver catalase. J. Mol. Biol., 152: 465499.

Pace, C. N., Vajdos, F., Fee, L., Grimsley, G. and Gray, T. 1995. How to measure and predict the molar absorption coefficient of a protein. Protein Sci., 4: 2411-2423.

Parsell, D.A., Kowal, A.S., Singer, M.A. and Lindquist, S. 1994. Protein disaggregation mediated by heat-shock protein HSP104. Nature., 372: 475-8.

Stromer, T., Ehrnsperger, M., Gaestel, M and Buchner, J. 2003. Analysis of the interaction of small heat shock proteins with unfolding proteins. J. Biol. Chem., 278: 18015-18021.

Switala, J. and Loewen, P. C. 2002. Diversity of properties among BLCs. Arch. Biochem. Biophys., 401: 145- 154. 